\title{
Technical, Energetic and Economic Optimization Analysis of Selection of Heat Source for Municipal Sewage Sludge Dryer
}

\author{
Mariusz Tańczuk ${ }^{1, *}$ and Wojciech Kostowski ${ }^{2}$ (D) \\ 1 Faculty of Mechanical Engineering, ul. Opole University of Technology, Mikołajczyka 5, 45-271 Opole, Poland \\ 2 Institute of Thermal Technology, ul. Silesian University of Technology, Konarskiego 22, \\ 44-100 Gliwice, Poland; wojciech.kostowski@polsl.pl \\ * Correspondence: m.tanczuk@po.edu.pl; Tel.: +48-664-475-355
}

check for updates

Citation: Tańczuk, M.; Kostowski, W. Technical, Energetic and Economic Optimization Analysis of Selection of Heat Source for Municipal Sewage Sludge Dryer. Energies 2021, 14, 316. https://doi.org/10.3390/en14020316

Received: 13 December 2020

Accepted: 6 January 2021

Published: 8 January 2021

Publisher's Note: MDPI stays neutral with regard to jurisdictional clai$\mathrm{ms}$ in published maps and institutional affiliations.

Copyright: $\odot 2021$ by the authors. Licensee MDPI, Basel, Switzerland. This article is an open access article distributed under the terms and conditions of the Creative Commons Attribution (CC BY) license (https:// creativecommons.org/licenses/by/ $4.0 /)$.

\begin{abstract}
The treatment of growing production of municipal sewage sludge has become a significant global problem. Drying of digested sewage sludge is a promising alternative to sludge disposal at dumping sites. The research objective of this study was to find the optimal heat source for a sludge drying plant in a large municipal sewage treatment plant (people equivalent: 250,000 ). Two boundary heat supply cases were analyzed in the paper: cogeneration of heat and power (CHP) units, internal combustion (IC) engines fired with natural gas, and plant supplied with a gas boiler. The aim of the research was to find the optimal size of the cogeneration unit cooperating with the gas boiler as heat sources for a given drying plant case with the maximum net present (NPV) value as the objective function. The results of the conducted optimization show higher profitability of cases with larger cogeneration unit. For the basic assumptions, the maximum NPV is obtained for the largest analyzed CHP unit: $1300 \mathrm{~kW}$ of thermal power output. Sensitivity analyses show that the varying gas and electricity prices can relocate the NPV maximum towards smaller CHP sizes. A supplementary energy analysis shows that implementing larger CHP units yields a higher energy efficiency of the system, up to 0.52 .
\end{abstract}

Keywords: municipal sewage sludge drying; energetic and economic optimization; energy efficiency; CHP; heat sources

\section{Introduction}

The handling of sewage sludge as the main by-product of wastewater treatment processes is one of the most significant challenges of sewage management [1]. In recent years, the global quantity of sludge output has increased sharply, mainly as a result of rapid urbanization. In particular, the relative growth of sludge production in China between 2006 and 2017 was reported to be as much as $100 \%$ : from $5.5 \times 10^{6} \mathrm{Mg}$ to $11 \times 10^{6} \mathrm{Mg}$ of dry weight (DS) [2]. In Poland, $0.583 \times 10^{6} \mathrm{Mg}$ of the sewage sludge was produced in 2018 according to [3]. For comparison, in 2007 this amount was less by around $25 \%$. By the year 2022 this quantity is expected to reach almost $0.750 \times 10^{6} \mathrm{Mg}$ [4] which represents almost $68 \%$ growth compared to 2010 . As stated in [5], the amount of sewage sludge produced in the European Union (EU) is also constantly growing: from $105 \times 10^{6} \mathrm{Mg}$ in 2008 to $135 \times 10^{6} \mathrm{Mg}$ expected by 2020 . Due to the environmental issues of constantly growing amount of sludge and the reinforcement of the regulations on its disposal [6], sewage sludge management has become a major global problem with critical significance in many countries, including Poland, the authors' country of origin [7]. According to [8], the increase in sewage sludge production has recently become a major environmental and economic issue due to the growing costs of pretreatment, transportation and disposal. Bearing in mind that $80-90 \%$ of contaminants from the wastewater are accumulated in the sewage sludge in [9], proper treatment of the sludge should be given particular importance.

Sewage sludge produced in wastewater treatment plants (WWTPs) is usually mechanically dewatered in order to minimize its volume, facilitate the transportation and increase 
the efficiency of energy utilization [10]. As reported in [11], nowadays, almost all of the large WWTPs are equipped with digester chambers to digest sewage sludge in order to generate biogas. Sewage sludge can also be used as a component for production of solid alternative fuel [12,13], gasified for high-quality syngas [14] or it can directly be combusted after drying, which at the same time provides a reduction of the mass and volume of the produced sewage sludge. Drying has also been a solution to the total prohibition of sewage waste disposal in Poland since 1 January 2016 [15]. The perspective of imposing the prohibition of sewage sediments disposal while forecasts suggests the increase of its amount has resulted in intensification of the problem of adequate sedimentary economy management in the last few years, both at a small (company-level) scale and at the global scale. It is predicted that in a few years, sludge management will not only become a crucial ecological and technical matter, but also an economic issue [4]. Considering the restrictions concerning sewage sludge storage and its use in agriculture, other methods of its management need to be found and applied. It seems that the thermal method of waste processing is one of the best possibilities. According to the current domestic municipal utilities management [16], thermal processing of sewage sludge has been accepted as the main method of its conversion (by 2020, about $60 \%$ of the total mass of such waste is supposed to be utilized using the thermal method). For comparison, 15 years ago in Poland, the use of the thermal method was non-existent, whereas in 2013 it exceeded 35\% [17].

In this paper, the issue of influence of law and market economy conditions on the profitability of building and operation of sewage sludge drying plants in Poland has been addressed. The legal and macroeconomic conditions are defined by the following factors:

- prohibition of storing dewatered sewage sludge;

- mechanisms of operational support for energy production directly related to the process of drying (i.e., support system for high-efficient cogeneration);

- costs of dewatered sewage sludge management;

- costs of dried sewage sludge management.

To estimate the influence of these factors, an example of a typical large municipal sewage treatment plant has been examined. In this plant, digested sludge is dewatered by means of a centrifuge to $20 \%$ of dry mass and then removed to a dumping site or partly used in agriculture. Such a way of managing sediments requires modernization because of the aforementioned unfavourable legislative conditions as well as due to the limited access to agricultural areas, due to environmental risks and the lack of interest in the dewatered product by potential consumers.

For the analyzed wastewater treatment plant, taking into consideration existing technological and environmental conditions, a medium-temperature design of the proposed sludge drying system has been considered. In the proposed drying installation, the method of drying provides hygienization. The final product is environmentally safe and does not put people at risk. Drying of sediments creates possibilities of mass reduction of the produced waste which makes it easier to store, transport and manage. Dried sludge produced in such a way can be naturally managed and used by the energy or cement industry.

The contribution of the study is thorough detailed analysis of the hybrid heat supply system integrated with sewage sludge drying process for various configuration scenarios. In the further part of this paper, a comparative economic analysis of the designed sludge drying plant has been made for two basic variants differing in the source of heat used for the process of drying: a plant with a CHP unit with internal combustion (IC) engines fired with natural gas and a plant with gas boiler as a source of the heat. The main goal of the analysis is to find the optimal share of cogeneration (CHP) implemented in conventional boiler-based system in terms of economic feasibility. The analyzed cases are subject to the same economic and legal conditions. The feasibility analysis was aimed at finding an optimum configuration of the heat source considering the maximum net present value (NPV) index.

Additionally, a sensitivity analysis of the analyzed project has been performed concerning some of the macroeconomic parameters (prices and costs). For the boundary heat 
source configuration scenarios, break-even points for the expected costs of digested sludge utilization critical for the NPV indicator were also found. Finally, an energy evaluation of the system was performed, and the total energy efficiency of the system was also derived for all the analyzed cases.

\section{System Description}

The analysis of applying a sewage sludge drying plant into a structure of a municipal sewage treatment plant size 200,000 - 250,000 people equivalent (PE) has been made. In the studied plant, sewage sludge management is characterized by certain features:

- there is a digestion of sewage sludge in closed digestion chambers;

- $\quad$ digested sludge is being dewatered by means of centrifuges and then hygienized;

- the amount of dry mass in the dewatered sludge varies from 20 to $25 \%$;

- dewatered sludge is deposited at a dumping site and it is partly used in agriculture;

- the annual amount of the dewatered sludge is c. $16,000 \mathrm{Mg}$.

For the sake of analysis, it has been assumed that to dry the dewatered sewage sludge, a medium temperature drying technology has to be applied. An exemplary model of how a belt drying plant works is presented in Figure 1.

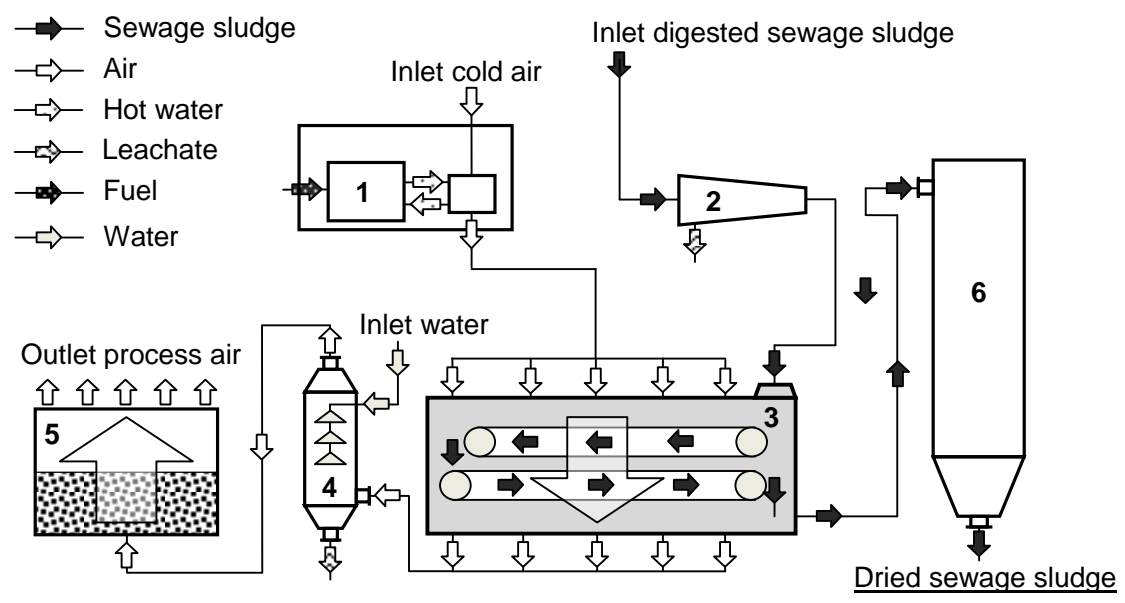

1. Heat source 2. Dewatering unit 3. Belt dryer 4. Scrubber 5. Biofilter

6. Dried sludge silo

Figure 1. Process diagram of drying in a belt sludge dryer integrated with a digested sludge dewatering station.

It should be underlined that apart from belt drying, a range of other technologies is available. The technologies can be divided into three main categories: convective drying, conductive drying and solar drying [4]. Nevertheless, there is possibility to combine different methods and consequently to apply hybrid dryers or combined dryers. The main categorization can further be detailed by technology. The most used technologies for sludge drying are convective belt dryers, flash dryers, fluidized bed dryers and rotary dryers. Three main technologies within the conductive drying plant are disc, paddle and thin film dryers [18]. A review on solar drying technology is presented in [19] including the main components, classifications and affecting parameters of the dryers. As reported in [20], sludge can be effectively dried in open sun dryers as well as in greenhouse solar dryers According to [21], at least $80 \%$ sludge volume reduction has been obtained in an open greenhouse pilot drying plant in Marrakesh city during the hot and cold seasons.

As introduced, in the analysed case, drying of sewage sludge will take place with the use of a medium temperature belt sludge dryer where the drying temperature is around $120^{\circ} \mathrm{C}$. The plant is equipped with two drying belts. Convective belt drying plants classified as such, can occur with direct or indirect heating: by hot air, hot steam gas or 
fuel gases. The process heat can be generated by means of fossil fuels (such as natural gas), biogas or biomass burners, it can be supplied by a heat exchanger receiving hot water generated in various types of heat sources or by a combination of the two.

While selecting a thermal configuration of the belt sewage sludge drying plant, it has to be considered that in the case of drying plants powered by conventional methods (i.e., on the basis of producing process heat in the process of fuel combustion) sources of heat can be used as follows:

- CHP modules fed with natural gas;

- CHP module fed with biogas produced in the process of sewage sludge digestion;

- $\quad$ gas fired boilers (natural gas or biogas);

- $\quad$ solid fuel fired boilers combusting dry sewage sludge (drying plant integrated with a dry sewage sludge incineration plant, where sludge is burned autothermally [18]).

The selection of technological and thermal configuration of a drying plant (heat source as well) is a result of a number of factors and boundary conditions, characterized by specific structures of sewage treatment plant. The economic criterion ought to be the final premise to make a decision about an investment. Regardless of a type of technology (CHP or typical gas boilers), heat will be produced in the form of hot water which will transfer energy needed to dry to the drying medium (air) in the heat exchanger system of a dryer. In that case, parameters which will have a particular influence on the profitability of the investment are as follows:

- $\quad$ the price of fuel (natural gas);

- the price of electrical energy (as the source of income);

- type of operational support (so-called cogeneration certificate system).

A given premise within the available technology of a heat source has become the basis to carry out an optimization analysis which the aim selecting an optimal heat source configuration considering the size of cogeneration system used. The size of a heat source, regardless of its type, results from the heat demand defined by the input stream of sewage sludge and by the water content in the sludge. In other words, the size of the required heat source results from the capacity of a drying plant. A correctly undertaken mass balance of the produced sludge is essential for an adequate selection of size (capacity) of a drying plant. In the analyzed case, the annual amount of dry mass in the sludge, after its dewatering in centrifuges, is assumed as $16,000 \mathrm{Mg}$. In Figure 2, an annual balance $(\mathrm{Mg} /$ year) of the sludge produced as well as basic parameters of capacity and efficiency of the drying process are presented. Annual and daily mass balance data of the plant can be found in Table 1.

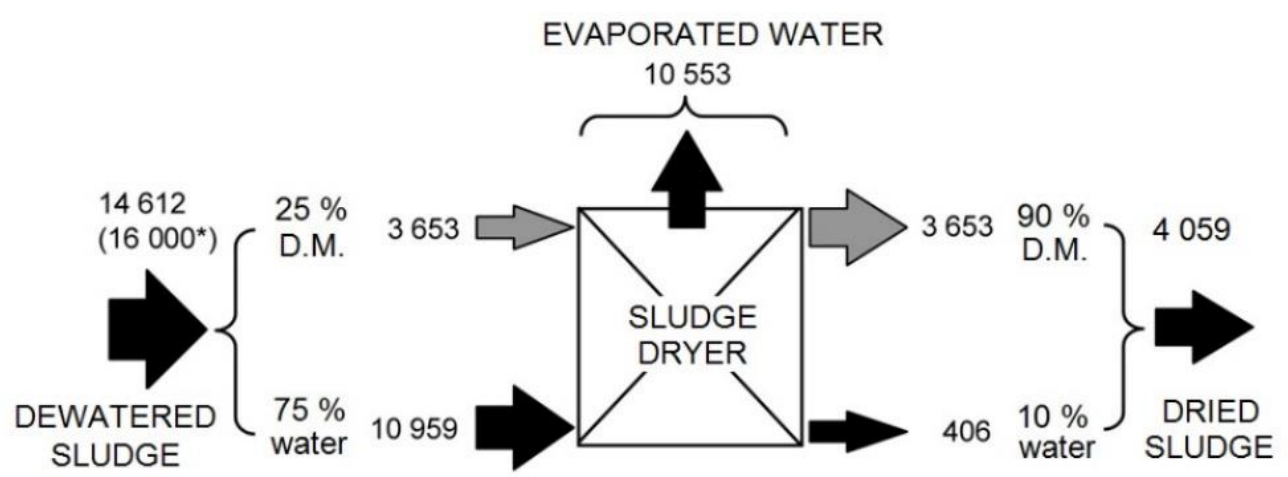

Figure 2. Annual balance of drying of dewatered digested sewage sludge, $\mathrm{Mg} /$ year. 
Table 1. Mass balance data of the analyzed drying plant.

\begin{tabular}{cccc}
\hline Parameter & Description & Annual, Mg & Daily, Mg \\
\hline Dewatered sludge flux (25\% of D.M.) & $\dot{M}_{s}$ & 14,612 & 43.8 \\
Evaporated water flux & $\dot{M}_{w}$ & 10,533 & 31.6 \\
Dried sludge flux (90\% of D.M.) & $\dot{M}_{d}$ & 4059 & 12.2 \\
\hline
\end{tabular}

The availability factor of a drying plant has been assumed at the level of 0.913 which corresponds to about $8000 \mathrm{~h}$ of operation within a year. Volumes of sewage sludge and water presented in Figure 2 result from a conversion of input value of annual dewatered sludge $(16,000 \mathrm{Mg})$ to corrected values regarding the availability factor. As a result, dewatered sewage sludge which is annually produced $(16,000 \mathrm{Mg})$ corresponds to $14,612 \mathrm{Mg}$ of sludge which is going to be dried and $10,553 \mathrm{Mg}$ of water evaporated during the drying process.

The amount of evaporated water is the basis for determining the heat power demand for the drying process. The most common way of setting an energy balance of the sludge drying process is to assume specific energy (heat) consumption, which is equal to the demand for heat needed to evaporate $1 \mathrm{~kg}$ ( or Mg) of water from the sludge. When choosing the drying technology, it is important to focus on efficient solutions: the more efficient process, the lower the specific heat demand. The specific heat demand occurring in drying plants installed around world depends on the drying technology and ranges from 0.5 to $1.2 \mathrm{kWh} / \mathrm{kg}$ of evaporated water [22-29]. In the analyzed case of the designed medium temperature belt drying plant, the value guaranteed in the contract is $1 \mathrm{kWh}$ of heat per $\mathrm{kg}$ of water. Another important factor influencing the energy balance is unitary demand of electricity. For the studied drying plant in a project-phase this value is equal to $0.085 \mathrm{kWh} / \mathrm{kg}$ according to the design documentation.

Based on the specified demand factors (thermal and electric) and with the use of mass balance data, the daily average heat and electricity power demands have been calculated and set as follows: $1300 \mathrm{~kW}$ of thermal power and $110 \mathrm{~kW}$ of electric power. Summary of design parameter of the analyzed belt dryer is presented in Table 2. It was the basis for further economic analysis and an optimization process.

Table 2. Main design parameter and performance data of a case study belt dryer.

\begin{tabular}{ccc}
\hline Parameter & Description & Value \\
\hline Inlet capacity & $\dot{m}_{s}$ & $1.83 \mathrm{Mg} / \mathrm{hr}$ \\
Sludge moisture at inlet & $r_{w s}$ & $80 \%$ \\
Drying temperature & $t_{d}$ & $120^{\circ} \mathrm{C}$ \\
Evaporation rate & $\dot{m}_{w}$ & $1.32 \mathrm{Mg} / \mathrm{hr}$ \\
Dried sludge production capacity & $\dot{m}_{d}$ & $0.51 \mathrm{Mg} / \mathrm{hr}$ \\
Sludge moisture at outlet & $r_{w d}$ & $10 \%$ \\
Specific heat consumption & $q_{t h}$ & $0.1 \mathrm{kWh} / \mathrm{kg} \mathrm{H}_{2} \mathrm{O}$ \\
Specific electricity consumption & $q_{e l}$ & $0.085 \mathrm{kWh} / \mathrm{kg} \mathrm{H}_{2} \mathrm{O}$ \\
Heat demand & $\dot{Q}_{d}$ & $1300 \mathrm{~kW}$ \\
Electric power demand & $N_{\text {eld }}$ & $110 \mathrm{~kW}$ \\
\hline
\end{tabular}

\section{Materials and Methods}

In this section, apart from the problem formulation and the applied methods, necessary key input data as well as intermediate energy performance results are presented in order to make the analysis easier to follow.

\subsection{Objective Function}

In the analyzed case, the size of the CHP unit used to supply the drying plant with heat was subject to economic optimization. In order to perform the optimization it was necessary to set the objective function. For the sake of common usage of the discounted 
method for calculations of investment projects feasibilities [30-36] it was the maximum of net present value (NPV) indices adopted in the methodology (NPV $\rightarrow$ max). Net present value can be derived by the Formula (1):

$$
\mathrm{NPV}=\sum_{t=0}^{N} \frac{C F_{t}}{(1+r)^{t}}
$$

In view of the typical expected lifetime of a sewage sludge drying plant not exceeding 20 years of operation, the NPV taken into account for the optimization process was the value calculated for the 15th year of operation $(n=15)$ :

$$
\mathrm{NPV}(15) \rightarrow \max
$$

It is important to state here that for the analyzed project, NPV is a measure influenced by a number of variables. Most of them are a function of technical parameters which should be obtained from mass and energy balances of the plant such as: plant capacity (input and output sewage sludge flows of a given and desired dry mass content), heat and electricity demand of the plant, fuel demand and annual operation time. In addition, NPV depends on the total investment expenditures, prices of fuel and energy and on the costs of both dried and dewatered sewage sludge management.

\subsection{Heat Source Configuration Modes}

The optimization procedure involved feasibility calculations for different heat source configurations. The analyzed heat source consists of a CHP unit with IC-engines fired with natural gas and a gas boiler. The aim of the optimization was to find optimum size of the CHP unit within the searched area of available thermal capacities: from $\dot{Q}_{C H P \min }$ to $\dot{Q}_{C H P \max }$. In other words: for the case of analyzed plant the optimization involves from $i=1$ to $n$ alternatives of $\mathrm{CHP}$ capacities.

It was assumed that the maximum CHP capacity $(i=n)$ corresponds to the total thermal power demand $\dot{Q}_{d}$ of the drying process. In this case, the heat source system is equipped only with a CHP unit and a back-up boiler of a capacity $\dot{Q}_{b b}=\dot{Q}_{C H P \max }=\dot{Q}_{d}$. In the minimum CHP size configuration scenario $\left(i=1 \rightarrow \dot{Q}_{C H P m i n}=0\right)$ sludge dryer is supplied with heat generated only in a gas boiler (backed-up with an additional boiler): $\dot{Q}_{b b}=\dot{Q}_{b}=\dot{Q}_{d}$. In all cases it can be stated that a gas boiler covers the heat demand which is not supplied by a CHP unit. The heat source configuration idea is presented schematically in Figure 3.

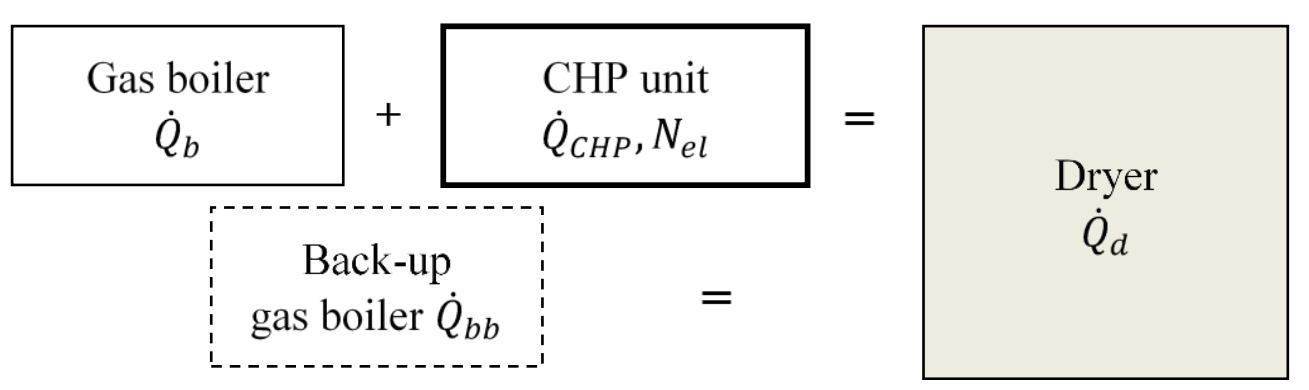

Figure 3. Heat source configuration applied for the analyzed sewage sludge dryer.

To carry out the heat source optimization, with regards to the discussed methodology, it was necessary to establish the following start assumptions:

- $\dot{Q}_{\text {CHPmin }}=0 \mathrm{~kW}$,

- $\dot{Q}_{C H P \max }=1300 \mathrm{~kW}$,

- $\quad$ searching step: $\Delta \dot{Q}_{C H P}=100 \mathrm{~kW}$. 
In the result, there were 14 configuration cases obtained $(n=14)$, as presented in Figure 4. To perform the economic calculation and to obtain NPV(15) values for all the assumed cases, it was necessary to derive the annual fuel (natural gas) consumption $F$ (including CHP consumption and boiler consumption: $F_{b}$ and $F_{C H P}$ ) of the heat source as well as the quantity of yearly produced electricity $E_{e l}$. It was done on the basis of the output power of a particular heat unit (CHP and/or boiler), its operation time $\tau_{0}$ and the assumed efficiencies, with the use of Equations (3) to (6):

$$
\begin{gathered}
F=F_{b}+F_{C H P} \\
F_{b}=\frac{\dot{Q}_{b} \cdot \tau_{0}}{L H V_{g} \cdot \eta_{b}} \\
F_{C H P}=\frac{E_{e l}}{L H V_{g} \cdot \eta_{e l}} \\
E_{e l}=N_{e l} \cdot \tau_{0}
\end{gathered}
$$

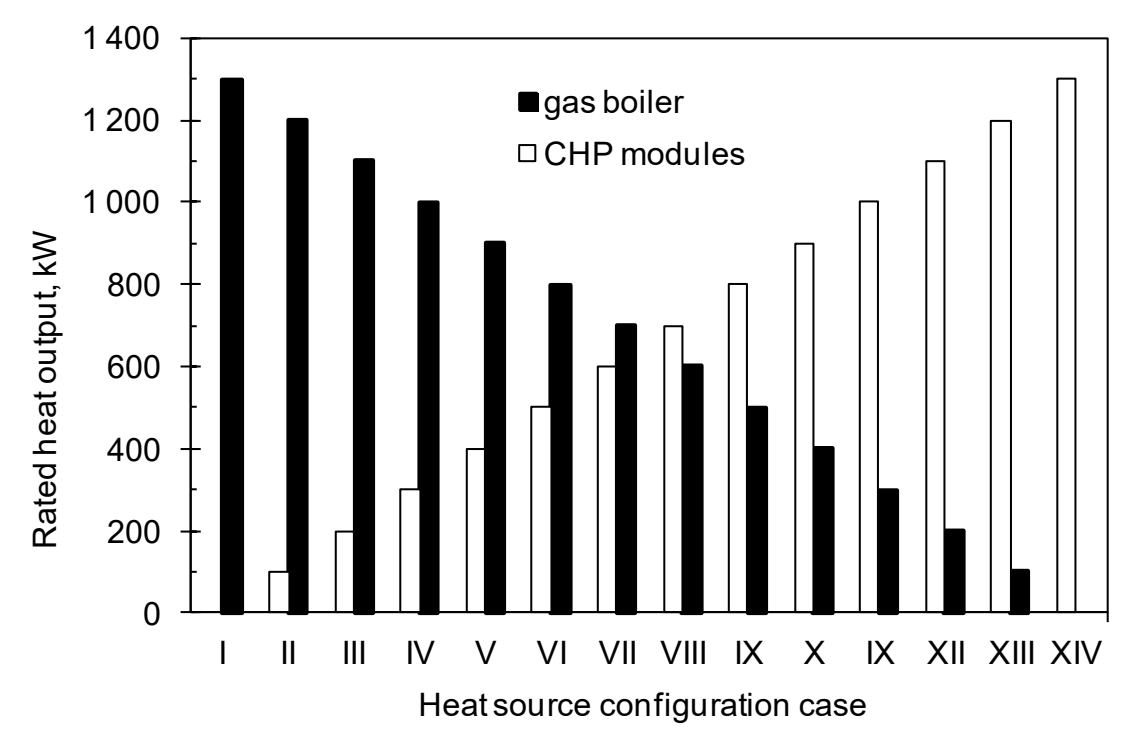

Figure 4. The CHP size cases created for the optimization process.

Electric power of the CHP unit $N_{e l}$ is the result of its thermal power output $\dot{Q}_{C H P}$. On the basis of the real plant data, it can be assumed that the electric power output of the maximum size CHP unit is sufficient to meet the internal demand of the drying plant as well as the demand of the sewage treatment plant. Electricity surpluses, if appearing, will be sold to the network. The data of heat and electricity production (including electricity

\begin{tabular}{|c|c|c|c|c|c|c|c|c|c|c|c|c|c|c|}
\hline \multirow{2}{*}{ Annual Amount } & \multicolumn{14}{|c|}{ Case } \\
\hline & 1 & 2 & 3 & 4 & 5 & 6 & 7 & 8 & 9 & 10 & 11 & 12 & 13 & 14 \\
\hline Heat from $\mathrm{CHP}$ unit, $\mathrm{TJ}$ & 0.0 & 2.9 & 5.8 & 8.6 & 11.5 & 14.4 & 17.3 & 20.2 & 23.0 & 25.9 & 28.8 & 31.7 & 34.6 & 37.4 \\
\hline Heat from gas boiler, TJ & 37.4 & 34.6 & 31.7 & 28.8 & 25.9 & 23.0 & 20.2 & 17.3 & 14.4 & 11.5 & 8.6 & 5.8 & 2.9 & 0.0 \\
\hline Electricity production, GWh & 0.00 & 0.64 & 1.28 & 1.92 & 2.56 & 3.20 & 3.84 & 4.48 & 5.12 & 5.76 & 6.40 & 7.04 & 7.68 & 8.32 \\
\hline Electricity to WWTP, GWh & 0.00 & 0.64 & 1.28 & 1.90 & 1.90 & 1.90 & 1.90 & 1.90 & 1.90 & 1.90 & 1.90 & 1.90 & 1.90 & 1.90 \\
\hline Electricity to the grid, GWh & 0.00 & 0.00 & 0.00 & 0.02 & 0.66 & 1.30 & 1.94 & 2.58 & 3.22 & 3.86 & 4.50 & 5.14 & 5.78 & 6.42 \\
\hline CHP fuel demand, $\mathrm{m}^{3} \times 10^{6}$ & 0.00 & 0.18 & 0.36 & 0.53 & 0.71 & 0.89 & 1.07 & 1.25 & 1.43 & 1.60 & 1.78 & 1.96 & 2.14 & 2.32 \\
\hline Boiler fuel demand, $\mathrm{m}^{3} \times 10^{6}$ & 1.30 & 1.20 & 1.10 & 1.00 & 0.90 & 0.80 & 0.70 & 0.60 & 0.50 & 0.40 & 0.30 & 0.20 & 0.10 & 0.00 \\
\hline
\end{tabular}
distribution) in each of analyzed cases as well as annual fuel consumption can be found in Table 3, in Section 3.4. Input data.

Table 3. Chosen operation data of the analyzed cases of heat source configuration. 
To conduct the economic calculations, it is also obligatory to define the total investment expenditures and the financing structure as well as the electricity and fuel prices, and management costs related with the dried and the dewatered sewage sludge. The input data used during the optimization, including results of technical calculations are also presented in Section 3.4. "Input data" of Table 3.

\subsection{Energy Performance of the System}

To evaluate the energy performance of the analyzed system it was necessary to find the energy efficiency of the drying plant. In this case, the fuel-product approach [37] was applied. It corresponds to the fact that the energy-related purpose of the drying installation is to increase the chemical energy of the sludge, however, the chemical energy of the sludge is not released in the plant. Within the applied approach, system efficiency can be defined by Equation (7):

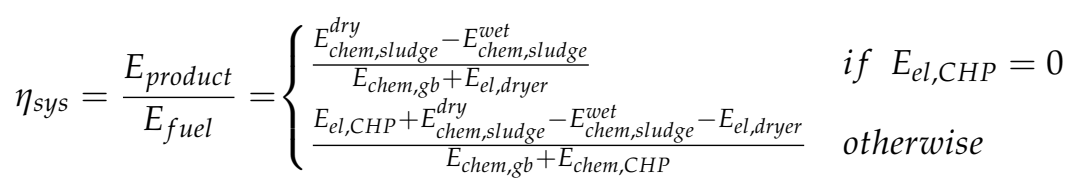

Heat fluxes generated by the gas boiler $\dot{Q}_{b}$ and by the CHP unit $\dot{Q}_{C H P}$, although significant for the intrinsic energy structure of the system, do not need to be considered in the overall energy balance and in the efficiency definition. These fluxes are only required for the drying purpose and are not exported beyond the system boundary for any other applications (e.g., space heating of other buildings in the plant, sales for external consumers). If such purposes would occur Formula (7) should be modified.

\subsection{Input Data}

On the basis of previous assumptions made on configuration modes of the heat source as well as data gained from a real project of constructing a municipal sewage sludge drying plant, the set of input data was prepared for the need of further investigation on NPV indices. At this stage, the energy balance was made with regard to the presented configuration modes to achieve production data. It needs to be outlined here that the approach based on calculating the annual energy effects of the analyzed systems without conducting hour-by-hour simulation is sufficient for the analysis. This is mainly due to the fact that heat demand of drying system stays at a relatively constant level throughout the year. Achieved set of data was then used to derive annual cash flows (CF) values. The results of calculation are shown in Table 3 and are made based on the following operational data and assumptions:

- average annual boiler heat production efficiency: $\eta_{b}=0.90$,

- CHP unit power to heat ratio: $\sigma=\mathrm{N}_{\mathrm{el}} / \dot{Q}_{\mathrm{CHP}}=0.3605 \cdot \mathrm{N}_{e l} 01137$ (power set in $\mathrm{kW}$ ) [38],

- $\quad$ average annual CHP electricity production efficiency: $\eta_{e l}=23.485 \cdot N_{e l}{ }^{00691}$ (power set in $\mathrm{kW}$ ) [38],

- lower heating value of natural gas: $L H V_{g}=35.5 \mathrm{MJ} / \mathrm{m}^{3}$.

General assumptions for the economic analysis have been made as follows:

- the project is located in Poland, cash flow calculations were performed in the local currency (PLN) and then converted to EUR (EUR to PLN exchange rate is 4.50),

- lifetime of the project is $n=15$ years,

- project is financed in $10 \%$ by own capital, in $30 \%$ by a subsidised loan and in $60 \%$ by Cohesion Fund subsidy,

- the weighted average rate of discount $r=7 \%$,

- the following incomes are taken into account: electricity sale, avoided costs of buying electricity, cogeneration tags sale, avoided costs of dewatered sludge management (treatment), dried sewage sludge sale, 
- following costs are taken into account: fuel (natural gas) buying costs, operational and maintenance costs (O\&M), personnel costs and costs of buying polyelectrolyte for the dewatering station.

The summary of all economic input data used in the analysis is presented in Table 4. During the first phase in the assessment of profitability, it is necessary to consider the value of the necessary investment expenditures $J_{0}$ and the means for funding this investment. For each of 14 analyzed cases, the amount of essential total investment outlays as well as the annual costs and operation incomes has been set. For the sake of the optimization performed, total investment expenditures were divided into outlays for constructing the drying plant and outlays for constructing the heat source system. Total investment cost of the drying plant, excluding the heat source, is the same for all investigated cases and comes from a real drying plant project. The costs of the heat source depend on the CHP unit size, regarding configuration modes presented before. The heat source investment cost was estimated on the basis of specific purchase costs of the CHP unit $i_{C H P}$ and gas boiler $i_{b}$ calculated from Equations (8) and (9) given in [38]:

$$
\begin{gathered}
i_{C H P}=-138.7 \cdot \ln \left(N_{e l}\right)+1727.1 \\
i_{b}=250 \cdot \dot{Q}_{b}{ }^{-0.13}
\end{gathered}
$$

Table 4. Basis economic data used for the optimization analysis.

\begin{tabular}{ccc}
\hline Economic Parameter & Description & Value \\
\hline Total investment outlays for the drying & $J_{0}{ }^{d}$ & $7.04 \mathrm{EUR}$ million \\
plant (excluding heat source) & $p_{e l}$ & $50 \mathrm{EUR} / \mathrm{MWh}$ \\
Electricity selling price & $p_{e l b}$ & $81 \mathrm{EUR} / \mathrm{MWh}$ \\
Electricity buying price & $p_{g}$ & $0.4 \mathrm{EUR} / \mathrm{m}^{3}$ \\
Natural gas price & $p_{C H P}$ & $25 \mathrm{EUR} / \mathrm{MWh}$ \\
Cogeneration tags (certificates) & $c_{d w s}$ & $59.5 \mathrm{EUR} / \mathrm{Mg}$ \\
Avoided specific cost of dewatered & $c_{d s}$ & $0 \mathrm{EUR} / \mathrm{Mg}$ \\
sludge treatment & & \\
Dried sludge price & &
\end{tabular}

Total heat source investment outlays are presented in Figure 5, separately for CHP units $J_{0}{ }^{C H P}$ and for gas boiler $J_{0}{ }^{b}$, including additional costs of equipment, connections and back-up units, on the basis of real project data.

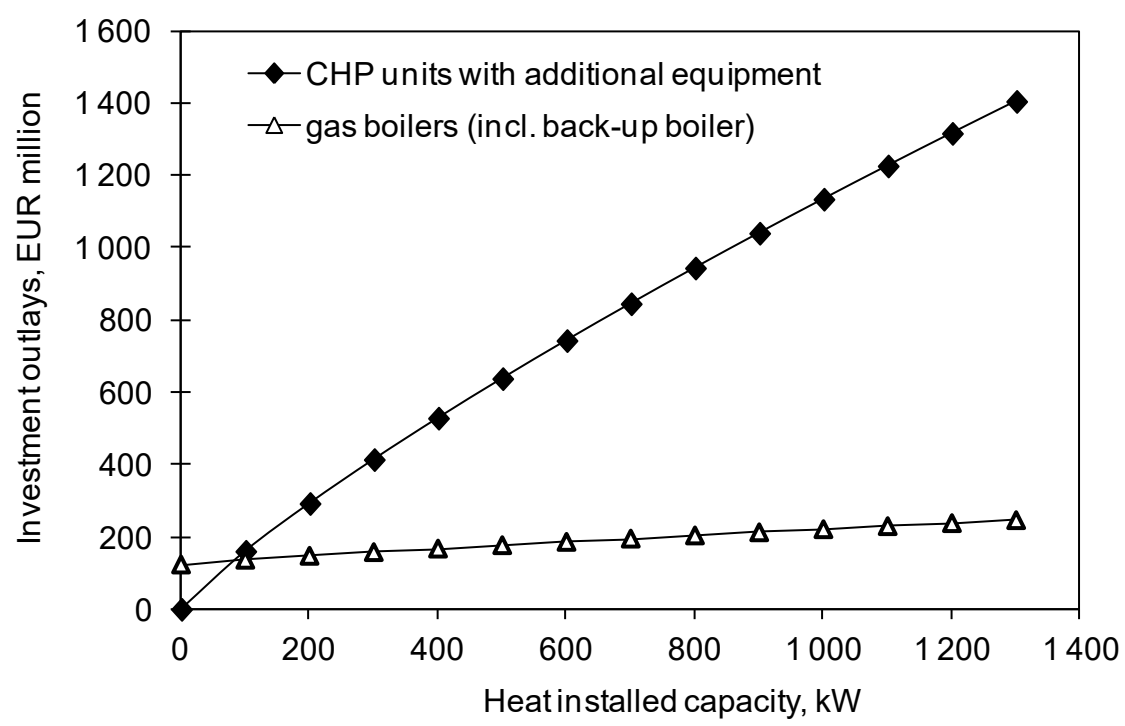

Figure 5. Investment cost of heat source units in function of the nominal heat capacity. 
Overall investment outlays of the project were calculated on the basis of formula:

$$
J_{0}=J_{0}{ }^{d}+J_{0}{ }^{C H P}+J_{0}{ }^{b}
$$

\section{Results and Discussion}

\subsection{Energy Performance Evaluation}

To evaluate the energy performance, it was first required to build an For the evaluation of the energy performance, energy balance of the plant. The balance was set for a one-hour period, so that the considered energy flows are numerically represented by power flows expressed in kW. Figures 6 and 7 show energy flows of the plant for two selected cases: case $2\left(\dot{Q}_{C H P}=100 \mathrm{~kW}\right)$ and case $13\left(\dot{Q}_{C H P}=1200 \mathrm{~kW}\right)$.

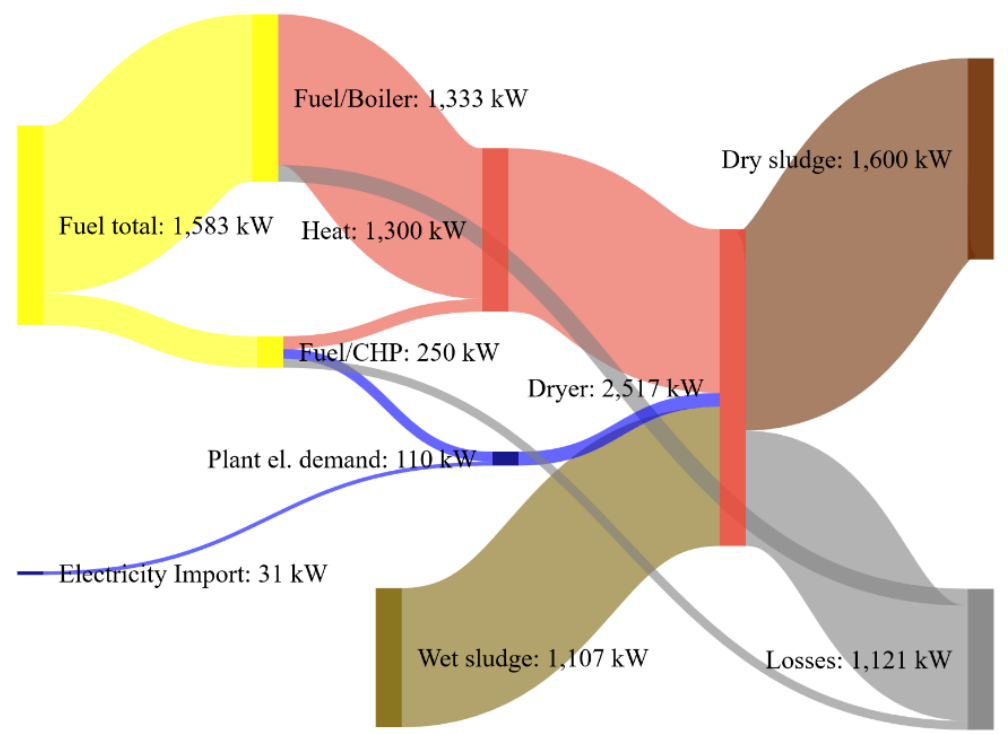

Figure 6. Energy flows in the drying plant—case 2.

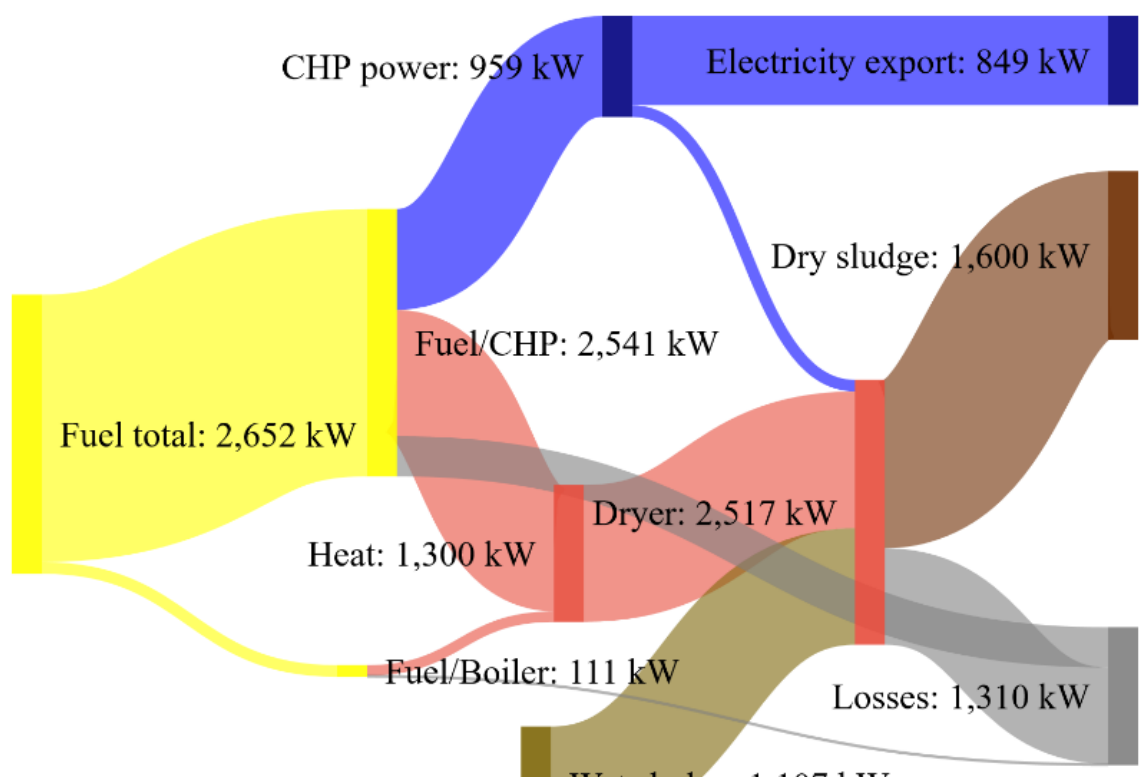

Wet sludge: $1,107 \mathrm{~kW}$

Figure 7. Energy flows in the drying plant-case 13. 
Figure 8 shows the efficiency indicator, as defined in Section 3.3., calculated for the analyzed cases of system configuration. The level of efficiency depends on the assumed heat source configuration and it is increasing for cases with higher sizes of cogeneration unit. System efficiency reaches the highest level (0.52) for the maximum size of the CHP unit.

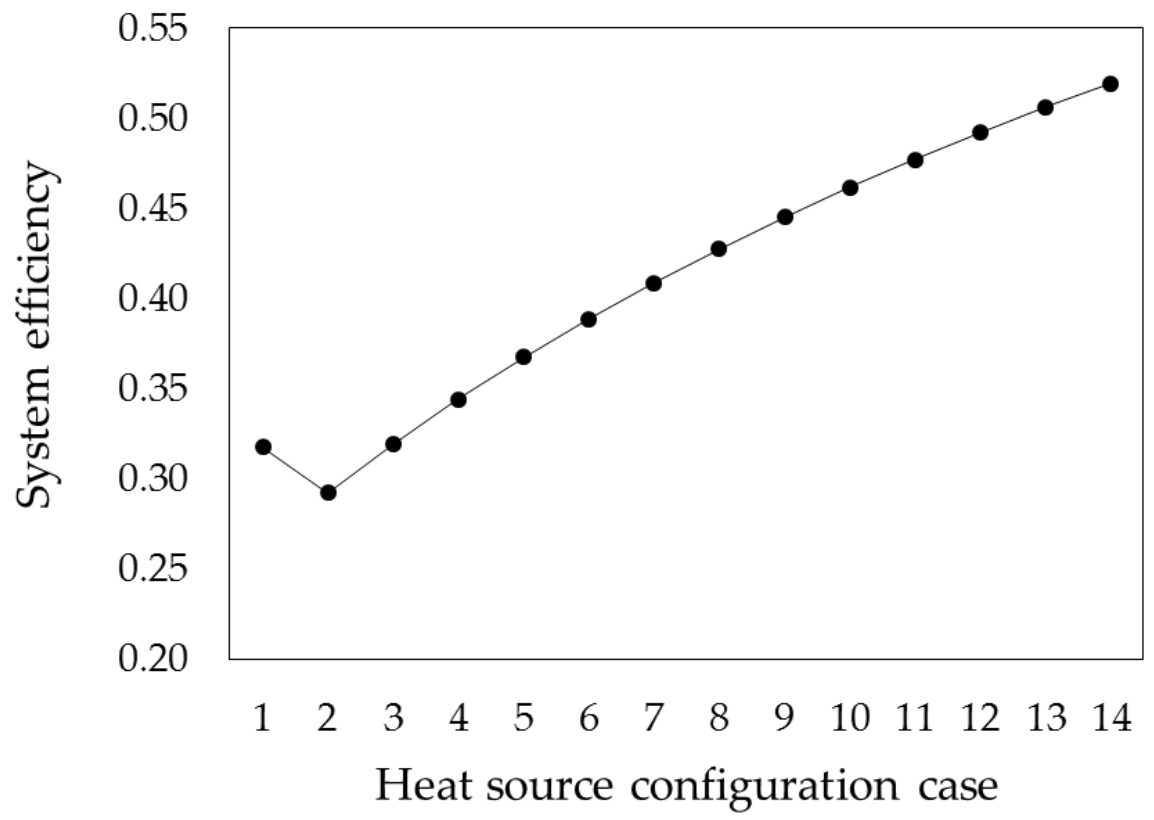

Figure 8. Energy efficiency of the system for the analyzed cases.

\subsection{Economic Optimization}

Optimization analysis has been undertaken for technical and economic assumptions specified in Tables 3 and 4 with the use of the optimization methodology described. For the analyzed project of building a municipal sewage sludge drying plant in an existing waste water treatment plant, the procedure of the search for the economic optimum was carried out for previously adopted base data inputs. According to the proposed methodology searching for the maximum NPV was carried out for $i=1$ to 14 cases of heat source configuration regarding the size of CHP unit.

Figure 9 contains a summary of the results of the NPV (15) index in the function of the $\mathrm{CHP}$ heat installed capacity. For the base conditions parameters, the requested maximum NPV (15) occurs at the upper limit of the searching area, i.e., for the CHP unit of the largest capacity $\left(\mathrm{NPV}(15)=\max\right.$ for $\left.\dot{Q}_{C H P}=1300 \mathrm{~kW}\right)$. Case no 1 , where the heat demand of the sludge dryer is covered only by a gas boiler $\left(\dot{Q}_{C H P}=0 \mathrm{~kW}\right)$ occurs absolutely unprofitable $(\mathrm{NPV}(15)=-3.65$ EUR million $)$. 


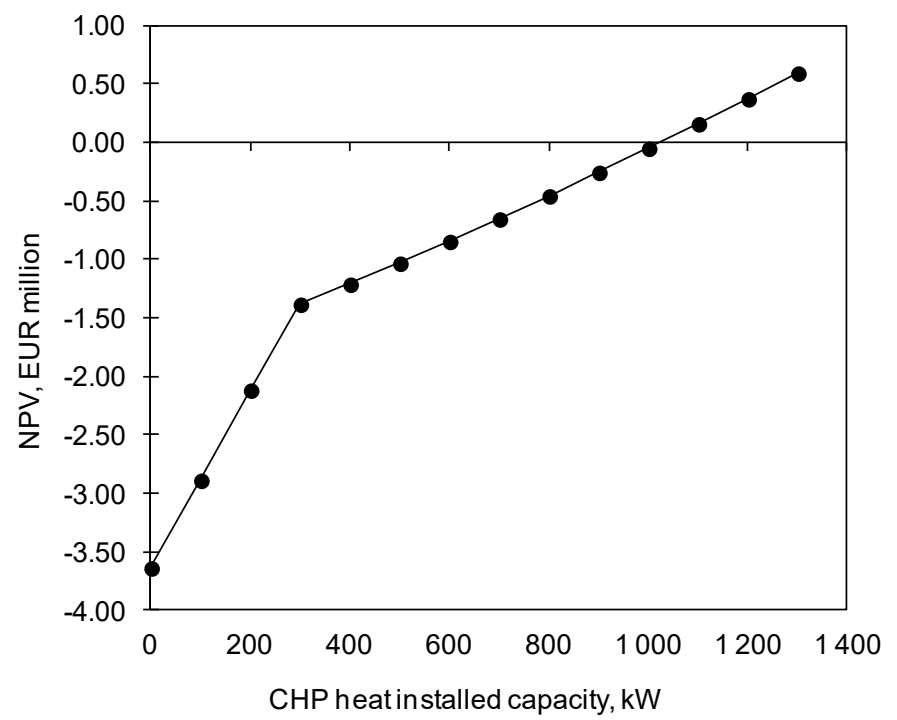

Figure 9. Results of optimization analysis.

On the basis of the results obtained, it can be stated that for the assumed basic conditions of the project, the minimum CHP size that provides economic profitability is defined by a thermal power output of around $1000 \mathrm{~kW}$. It is justified then to state that the higher is the share of the CHP unit in supplying the thermal demand for the drying process, the better are the economic results of the project.

\subsection{Sensitivity Analysis}

Due to unstable economic conditions (i.e., energy and fuel prices) it is worth checking how sensitive the NPV index is to variations of the chosen economic variables. It is expected that changes in selected input values would also change the location of maximum of an objective function (maximum of the NPV function).

The sensitivity analysis included calculations for the following economical inputs, firstly set as basic values to the optimization analysis:

- $\quad$ price of natural gas used for heat production;

- price of electricity generated by CHP unit (both selling and buying prices were changed simultaneously).

Results of the investigation for variable prices can be found in Figures 10 and 11. It can be noticed that increasing natural gas prices by more than $20 \%$ is relocating the position of the optimal NPV index towards CHP units with smaller installed thermal capacities and, in the same time, it is significantly diminishing the level of net present values. The adequate change of gas price for values lower then the basic one (change by $-20 \%$ and more) results in the improvement of profitability for all cases and it provides a positive NPV value even for the case without CHP unit supply. 


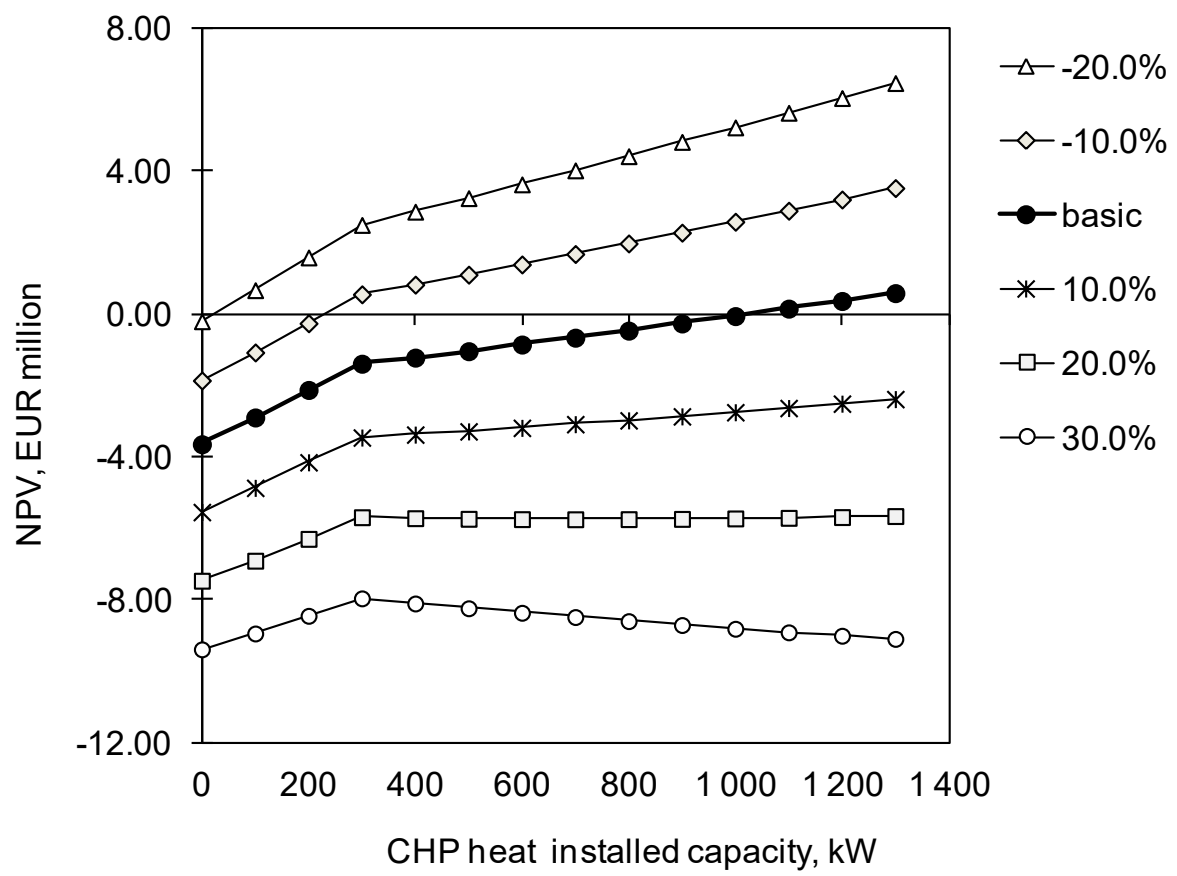

Figure 10. Sensitivity of the location of net present value (NPV(15)) function maximum for varying natural gas price.

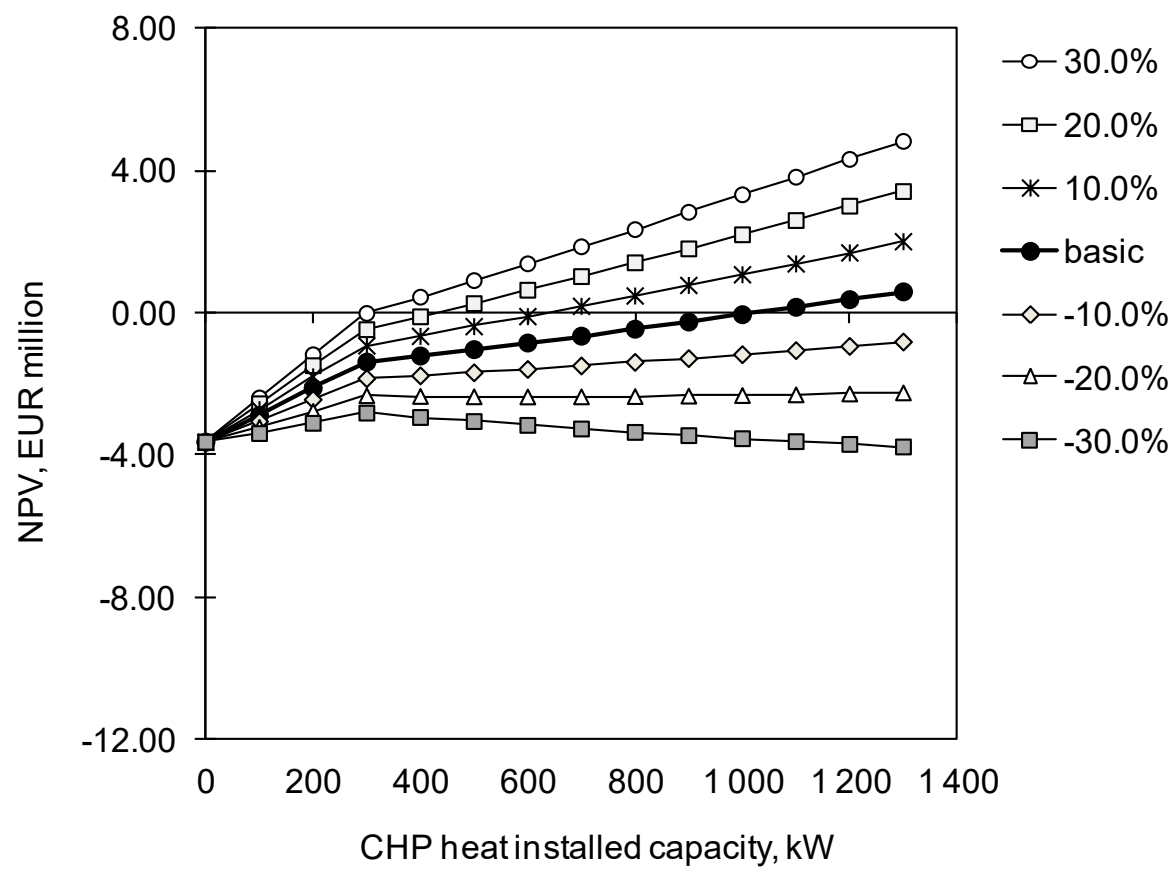

Figure 11. Sensitivity of the location of NPV(15) function maximum for varying electricity prices.

The set of optimization curves presented in Figure 11 indicates that decreasing electricity prices shifts the maximum of the NPV(15) towards the CHP with a smaller capacity. In the case of increasing electricity prices (by 10\% and more), the location of maximum of the objective function remains at the upper limit of the domain (at the maximum size of the CHP unit) but the profitability of all examined cases is increasing. If the electricity price growth exceeds 30\%, the NPV value becomes positive already for $300 \mathrm{~kW}$ of CHP thermal capacity.

Figure 12 presents results of the sensitivity analysis made for the two boundary cases: case 1 without $\mathrm{CHP}$ unit and case no 14 where the $\mathrm{CHP}$ unit covers all the heat 
demand of a drying plant. It can be seen that break-even points (BEP) of NPV(15) is equal to 58.4 EUR/Mg for the "pure CHP" case and 66.5 EUR/Mg for the "pure boiler" case. This comparative sensitivity analysis confirms a higher profitability of a sludge drying plant equipped with a CHP unit as a heat source for the process.

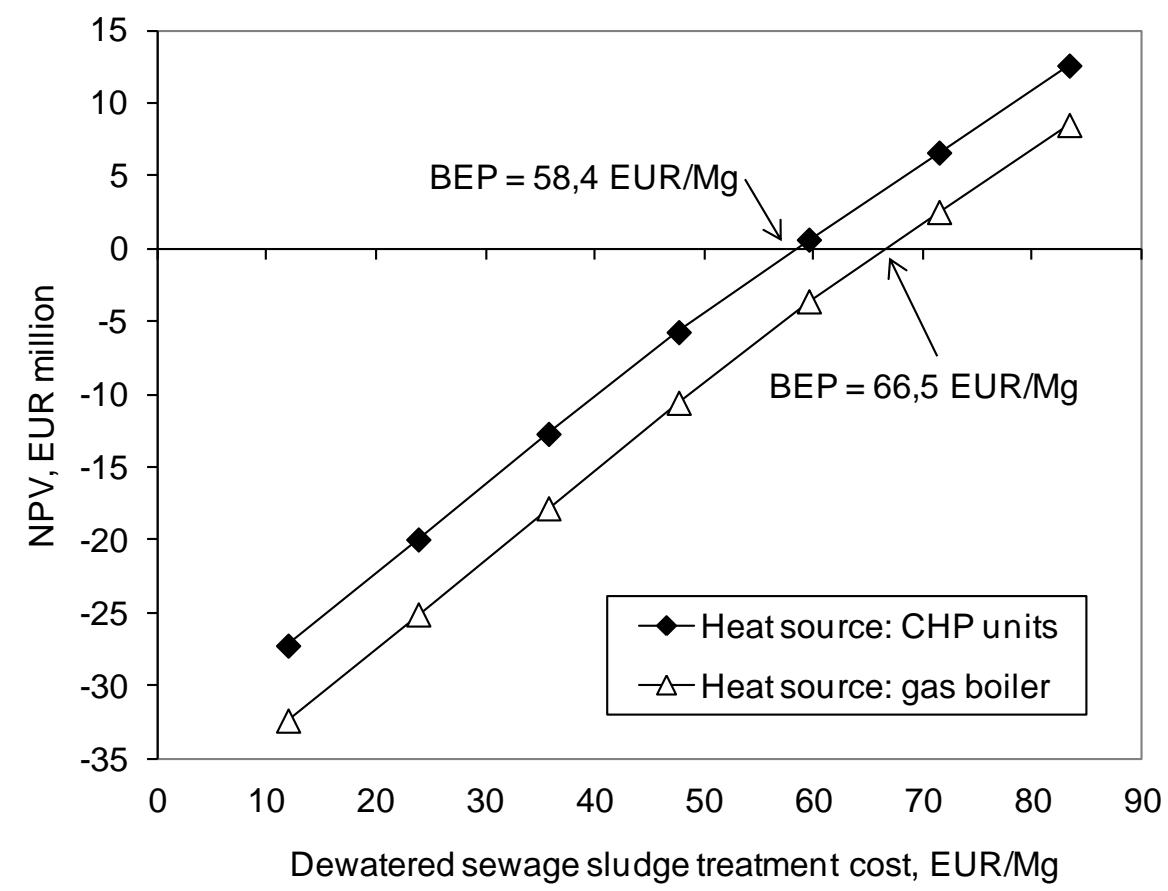

Figure 12. NPV(15) index in function of the dewatering sludge treatment cost (Cases 1 and 14).

\section{Conclusions}

The project of retrofitting an existing waste water treatment plant with a sewage drying plant integrated with a heat source has been discussed in the paper. The project represents a common way to undertake sewage sludge treatment and the results of calculations confirm that it can be a profitable solution under certain technological and economic circumstances.

On the basis of the conducted optimization for the examined drying plant it was possible to find the optimal size of the cogeneration block (CHP) used as a heat source for the drying process which ensures good feasibility of the project. It was established that for the basic economic assumptions the optimal NPV(15) parameter is found at the end of the range of the argument of the objective function, i.e., for the highest capacity of the CHP. However, sensitivity analysis shows the possibility of changing the location of NPV index for smaller CHP capacities. A heat source composed of a small size CHP unit cooperating with a gas boiler or even equipped with a boiler as the only heat producing unit can become an optimal solution on the condition of a sufficient change in natural gas or electricity prices (respectively decrease or increase).

According to the results of the comparative analysis made for "boundary" cases (boiler or cogeneration unit as the only source of process heat) one can see the meaningful influence of dewatering sludge treatment cost, which can be avoided in the case of constructing a sludge dryer in a waste water treatment plant. The higher the value of such avoided costs, the better the justification for building an in-house drying plant instead of commissioning sludge treatment to an external entity.

Author Contributions: Conceptualization, M.T.; methodology, M.T. and W.K.; formal analysis, M.T.; investigation, M.T. and W.K.; resources, M.T.; data curation, M.T.; writing-original draft preparation, M.T.; writing—review and editing, M.T.; visualization, M.T. and W.K.; supervision, M.T. All authors have read and agreed to the published version of the manuscript.

Funding: This research received no external funding. 
Institutional Review Board Statement: Not applicable.

Informed Consent Statement: Not applicable.

Data Availability Statement: Data sharing not applicable.

Conflicts of Interest: The authors declare no conflict of interest.

\section{References}

1. Fytili, D.; Zabaniotou, A. Utilization of sewage sludge in EU application of old and new methods-A review. Renew. Sustain. Energy Rev. 2008, 12, 116-140. [CrossRef]

2. Chu, L.; He, W. Toxic metals in soil due to the land application of sewage sludge in China: Spatiotemporal variations and influencing factors. Sci. Total Environ. 2021, 757, 143813. [CrossRef] [PubMed]

3. General Statistics Office in Poland. Available online: https://stat.gov.pl/en/ (accessed on 15 November 2020).

4. Tańczuk, M.; Kostowski, W.J.; Karaś, M. Applying waste heat recovery system in a sewage sludge dryer-A technical and economic optimization. Energy Convers. Manag. 2016, 125, 121-132. [CrossRef]

5. Đurđević, D.; Blecich, P.; Jurić, Ž. Energy Recovery from Sewage Sludge: The Case Study of Croatia. Energies 2019, $12,1927$. [CrossRef]

6. Wiśniowska, E.; Grobelak, A.; Kokot, P.; Kacprzak, M. Sludge legislation-comparison between different countries. In Industrial and Municipal Sludge; Prasad, M.N.V., de Campos Favas, P.J., Vithanage, M., Venkata Mohan, S., Eds.; Elsevier Inc.: Amsterdam, The Netherlands, 2019; pp. 201-224.

7. Werle, S.; Wilk, K.R. A review of methods for the thermal utilization of sewage sludge: The Polish perspective. Renew. Energy 2010, 35, 1914-1919. [CrossRef]

8. Di Capua, F.; Spasiano, D.; Giordano, A.; Adani, F.; Fratino, U.; Pirozzi, F.; Esposito, G. High-solid anaerobic digestion of sewage sludge: Challenges and opportunities. Appl. Energy 2020, 278, 115608. [CrossRef]

9. Agoro, M.A.; Adeniji, A.O.; Adefisoye, M.A.; Okoh, O.O. Heavy Metals in Wastewater and Sewage Sludge from Selected Municipal Treatment Plants in Eastern Cape Province, South Africa. Water 2020, 12, 2746. [CrossRef]

10. Wu, B.; Dai, X.; Chai, X. Critical review on dewatering of sewage sludge: Influential mechanism, conditioning technologies and implications to sludge re-utilizations. Water Res. 2020, 180, 115912. [CrossRef]

11. Mirmasoumi, S.; Ebrahimi, S.; Saray, R.K. Enhancement of biogas production from sewage sludge in a wastewater treatment plant: Evaluation of pretreatment techniques and co-digestion under mesophilic and thermophilic conditions. Energy 2018, 157, 707-717. [CrossRef]

12. Wzorek, M.; Troniewski, L. Application of sewage sludge as a component of alternative fuel. In Environmental Engineering; Dudzińska, M., Pawłowski, L., Eds.; Taylor \& Francis Group: New York, NY, USA, 2007; pp. 311-316.

13. Wzorek, M.; Tańczuk, M. Production of biosolid fuels from municipal sewage sludge: Technical and economic optimization. Waste Manag. Res. 2015, 33, 704-714. [CrossRef]

14. Kokalj, F.; Arbiter, B.; Samec, N. Sewage sludge gasification as an alternative energy storage model. Energy Convers. Manag. 2017, 149, 738-747. [CrossRef]

15. Regulation of the Minister of Economy and Labour of 7 September 2005 on the Criteria and Procedures for Admission of the Waste for Disposal in the Landfill of a Given Type (Journal of Laws No. 186, Item. 1553, Dated 28 September 2005) with Subsequent Changes. Available online: http:/ / isap.sejm.gov.pl/ (accessed on 25 May 2020). (In Polish)

16. Sładeczek, F.; Niemczyk, P. Ecological and technical aspects of sewage sludge co-incineration in the cement industry and power generation. Arch. Spalania 2006, 6, 86-96. (In Polish)

17. Pająk, T. Thermal methods as leading option of municipal sewage sludge treatment. Instal. Theory Pract. Install. 2013, 10, 20-25. (In Polish)

18. Bennamoun, L.; Arlabosse, P.; Léonard, A. Review on fundamental aspect of application of drying process to wastewater sludge. Renew. Sustain. Energy Rev. 2013, 28, 29-43. [CrossRef]

19. El Hage, H.; Herez, A.; Ramadan, M.; Bazzi, H.; Khaled, M. An investigation on solar drying: A review with economic and environmental assessment. Energy 2018, 157, 815-829. [CrossRef]

20. Singh, P.; Shrivastava, V.; Kumar, A. Recent developments in greenhouse solar drying: A review. Renew. Sustain. Energy Rev. 2018, 82, 3250-3262. [CrossRef]

21. Belloulid, M.O.; Hamdi, H.; Mandi, L.; Ouazzani, N. Solar Greenhouse Drying of Wastewater Sludges Under Arid Climate. Waste Biomass Valorization 2017, 8, 193-202. [CrossRef]

22. Li, H.; Chen, Q.; Zhang, X.; Finney, K.N.; Sharifi, V.; Swithenbank, J. Evaluation of a biomass drying process using waste heat from process industries: A case study. Appl. Therm. Eng. 2012, 35, 71-80. [CrossRef]

23. Holmberg, H. Biofuel Drying as a Concept to Improve the Energy Efficiency of an Industrial CHP Plant. Ph.D. Thesis, Helsinki University of Technology, Espoo, Finland, 2007.

24. Bruce, D.M.; Sinclair, M.S. Thermal Drying of Wet Fuels: Opportunities and Technology; EPRI Report (TR-107109 4269-01); Electric Power Research Institute: Washington, DC, USA, 1996.

25. Amos, W.A. Report on Biomass Drying Technology; NREL Contract No. DE-AC36e83CH; National Renewable Energy Laboratory: Golden, CO, USA, 1998. 
26. Li, T.; Li, C.; Li, B.; Li, C.; Fang, Z.; Zeng, Z.; Ou, W.; Huang, J. Characteristic analysis of heat loss in multistage counter-flow paddy drying process. Energy Rep. 2020, 6, 2153-2166. [CrossRef]

27. Van Deventer, H.C. Industrial Superheated Steam Drying; TNO Report R 2004/239; TNO: The Hague, The Netherlands, 2004.

28. Fagernäs, L.; Brammer, J.; Wilen, C.; Lauer, M.; Verhoeff, F. Drying of biomass for second generation synfuel production. Biomass Bioenergy 2010, 34, 1267-1277. [CrossRef]

29. Sarker, M.; Ibrahim, M.; Aziz, N.A.; Salleh, P.M. Energy and rice quality aspects during drying of freshly harvested paddy with industrial inclined bed dryer. Energy Convers. Manag. 2014, 77, 389-395. [CrossRef]

30. Wang, Y.; Wang, J.; Zhang, X.; Grushecky, S. Environmental and Economic Assessments and Uncertainties of Multiple Lignocellulosic Biomass Utilization for Bioenergy Products: Case Studies. Energies 2020, 13, 6277. [CrossRef]

31. Economopoulos, A.P. Technoeconomic aspects of alternative municipal solid wastes treatment methods. Waste Manag. 2010, 30, 707-715. [CrossRef] [PubMed]

32. Tańczuk, M.; Radziewicz, W.; Olszewski, E.; Skorek, J. Projected configuration of a coal-fired district heating source on the basis of comparative technical-economical optimization analysis. E3s Web Conf. 2017, 19, 01007. [CrossRef]

33. Pettinau, A.; Ferrara, F.; Amorino, C. Combustion vs. gasification for a demonstration CCS (carbon capture and storage) project in Italy: A techno-economic analysis. Energy 2013, 50, 160-169. [CrossRef]

34. Osborne, M.J. A resolution to the NPV-IRR debate? Q. Rev. Econ. Financ. 2010, 50, 234-239. [CrossRef]

35. Skorek-Osikowska, A.; Bartela, Ł.; Kotowicz, J.; Sobolewski, A.; Iluk, T.; Remiorz, L. The influence of the size of the CHP (combined heat and power) system integrated with a biomass fueled gas generator and piston engine on the thermodynamic and economic effectiveness of electricity and heat generation. Energy 2014, 67, 328-340. [CrossRef]

36. Wessel, M.; Madlener, R.; Hilgers, C. Economic Feasibility of Semi-Underground Pumped Storage Hydropower Plants in Open-Pit Mines. Energies 2020, 13, 4178. [CrossRef]

37. Torres, C.; Serra, L.; Valero, A. The productive structure and thermoeconomic theories of system optimization. In Thermodynamics and the Design. Analysis and Improvement of Energy Systems; Duncan, A., Fiszdon, J., O’Neal, D., Braven, K., Eds.; ASME: New York, NY, USA, 1996; pp. 429-536.

38. Kalina, J.; Skorek, J. Gas-Fired Cogeneration Plants, 1st ed.; WNT: Gliwice, Poland, 2004. 